\section{Hypothesis: in COPD, a pound of cure may be better than an ounce of prevention}

\author{
Stephen I Rennard, ${ }^{1}$ Jorgen Vestbo ${ }^{2}$
}

Chronic obstructive pulmonary disease (COPD) is currently the fourth leading cause of death in the USA. ${ }^{1}$ Its defining feature is limitation of expiratory airflow, which is usually relentlessly progressive. Current therapies have meaningful, but limited benefits. For those who have resting hypoxaemia, supplemental oxygen improves survival. Rehabilitation can improve health status and exercise performance. However, neither of these treatments alters lung function or the rate at which it declines. Volume reduction surgery, by removing the most dysfunctional parts of the lung, can reduce exacerbations ${ }^{2}$ and improve lung function, performance, symptoms and survival, but only in a subset of patients, and the effects are limited, both in magnitude and in duration. ${ }^{3} 4$ Currently available pharmacotherapy, including bronchodilators and combinations of bronchodilators and inhaled corticosteroids, modestly improve airflow and symptoms and reduce exacerbations. ${ }^{5} 6$ Statistically significant effects in slowing the rate at which lung function is lost have been reported with pharmacotherapy, ${ }^{7}$ but the clinical importance of the benefits achieved remain uncertain.

With this background, a major goal for novel therapy in COPD is to alter the natural history of the disease.

The classic study of Fletcher and colleagues $^{8}$ provided the basis for current understanding of the natural history of COPD and has guided attempts at altering its course. The 'British Postal Worker's Study' included 792 men who were evaluated for a period of eight years. Based on this study, Fletcher and colleagues suggested that normal individuals lost lung function at an accelerating rate with age. Individuals who were exposed, for

\footnotetext{
${ }^{1}$ Department of Internal Medicine, Pulmonary, Critical Care, Sleep \& Allergy Division, University of Nebraska Medical Center, Omaha, Nebraska, USA; ${ }^{2}$ Respiratory Research Group, Manchester Academic Health Sciences Centre, University of Manchester, UK

Correspondence to Stephen I Rennard, University of Nebraska Medical Center, 985910 Nebraska Medical Center, Omaha, Nebraska 68198-5910, USA; srennard@unmc.edu
}

example, to cigarette smoke, and who were susceptible, experienced an accelerated rate of decline in lung function. A portion of these would eventually be diagnosed with COPD. To their credit, Fletcher and colleagues recognised that their 'model' was an extrapolation based on a limited data set and that only one parameter of COPD, airflow limitation, was considered.

The first large study designed to alter the course of COPD, and the only one that has demonstrated a positive effect testing the a priori hypothesis, was the 'Lung Health Study'. 10 This trial assessed smoking cessation, which was effective in slowing loss of lung function and the anticholinergic ipratropium, which was not. The sample size estimates were based on data from Fletcher and colleagues, ${ }^{8}$ as well as other studies, suggesting that COPD patients would be losing lung function measured as the $\mathrm{FEV}_{1}$ at an average rate of $60 \mathrm{ml} /$ year in contrast to normal, which is closer to $20 \mathrm{ml} /$ year. $^{11}$ The study was powered with a target effect size of improving the COPD patients by half of the difference, that is to a $40 \mathrm{ml} /$ year loss of $\mathrm{FEV}_{1}$. Two thousand subjects in three groups were studied over five years to demonstrate the benefit of smoking cessation in a post hoc analysis and the lack of effect of ipratropium in an intention to treat analysis. ${ }^{9}$ A subsequent follow-up at 11 years demonstrated the benefit of the smoking cessation intervention in the intention to treat group. ${ }^{10}$

The size and duration of the lung health progressive loss of $\mathrm{FEV}_{1}$ in COPD. In order to have smaller and faster (and less expensive) clinical trials, many investigators have sought alternate measures. This has led to a new understanding of the complexity of COPD as well as to a number of alternate measures of the disease. ${ }^{12-15}$ However, the goal of all these efforts remains slowing the natural history of COPD, the goal sought by the Lung Health Study based on the model of Fletcher and colleagues. ${ }^{8}$ It may be paradoxical, but a much more ambitious goal, that is the cure of COPD, may be more easily achieved. study were a function of the slowly
The large numbers of subjects and the long timeframes required when $\mathrm{FEV}_{1}$ is used as the measure of disease progression in COPD depend on the variance in the measure, which is well established at $55 \mathrm{ml}$, and the anticipated effect size, for which a goal of $20 \mathrm{ml} /$ year improvement remains an elusive target. However, most diagnosed COPD patients have lost 50-70 per cent of the lung function present in young adulthood, a loss of perhaps 2000-2500 $\mathrm{ml}$ Saving an additional $20 \mathrm{ml} /$ year for the remainder of an individual's life could be important, but is an extremely modest goal. In contrast, restoring even half of the lost function, for example 1000-1250 ml, would represent a much more robust treatment.

Therapy to cure COPD is not so farfetched. A number of studies support the potential for such therapy. Retinoic acid, for example, can restore lung tissue in rodents with emphysema, ${ }^{16}$ though studies in man have been without clear benefit. ${ }^{17}$ Recognition that a selective retinoic acid receptor agonist may have greater effects offers a potential means to advance this line of therapy. ${ }^{18}$ Other agonists including hepatocyte growth factor ${ }^{19}$ and granulocyte colony stimulating factor ${ }^{20}$ may also have the capability of stimulating alveolar wall formation following the development of emphysema. The latter is of particular interest, as recruitment of circulating stem/ precursor cells may play a role. The ability of circulating cells to enter the lung, to become parenchymal cells and participate in repair, ${ }^{20-22}$ suggests a number of therapeutic strategies. For example, it may be possible to administer a stem/precursor cell population that can subsequently be stimulated with pharmacologic mediators. The availability of stem cells for clinical trials suggests that this type of strategy could be pursued in the near future. ${ }^{23}$

Lung repair can also be conceptualised for airways disease. In this context, airway fibrosis likely resembles fibrosis in other tissues, which, despite long held assumptions, may be reversible. ${ }^{24} 25$ In some settings, airways fibrosis does appear to resolve. $^{26}$ In addition, the goblet cell metaplasia that is frequently present in patients with chronic bronchitis can reverse. ${ }^{27}$ Thus, strategies aimed at altering airway structure are also entirely feasible.

Despite biological plausibility, therapy to restore lung function is generally regarded as a 'pie in the sky' type of goal. Paradoxically, it may be much easier to develop and more practical to implement in the clinical setting than the more modest goal of slowing disease progression. 
A therapy in severe COPD that would result in an effect size of $1000 \mathrm{ml}$ in $\mathrm{FEV}_{1}$ would only require a handful of individuals in each group to have a 90 per cent chance of showing a benefit with a $p<0.05$. The timeframe would depend on the biology, but the ability of retinoic acid to stimulate alveolar wall formation in the animal model is easily detected in two weeks. Rapid effects discernable over short timeframes in small numbers of subjects would expedite dose ranging, and would thus simplify the need for biomarker intermediates and reduce the uncertainties inherent in the use of surrogates. Curative therapies, therefore, are likely to be developed over much shorter timeframes in smaller numbers of subjects and may have less risk of failure in phase III than treatments that slow disease progression. All these would reduce development costs.

Curative therapies are also likely to have advantages in clinical practice. Therapy designed to prevent disease progression is most effective when given in the presence of relatively mild disease. Serious adverse effects are not readily acceptable in this setting. In contrast, a curative therapy could be used exclusively in patients with very severe disease, in whom quality of life and survival are substantially compromised. This is particularly important for approaches that target mechanisms of cell proliferation and differentiation, which may have serious side effects, for example malignancy or fibrosis. For patients with very severe COPD, however, the potential risk of malignancy may be far outweighed by the reality of severe COPD.

Curative therapy is also likely to have fiscal advantages in clinical practice. Given the heterogeneity of COPD, it is likely that a 'restorative' therapy would be effective in a subset of COPD patients. A therapy designed to restore alveolar wall will only be of benefit in those with emphysema, for example. Thus, only a portion of the COPD population would be candidates for treatment. In addition, treatments may need to be given over relatively short timeframes. Thus, from a payor's perspective, a curative therapy could have significant savings due to the reduced number of treated patients and the reduction in long term visits and other supportive care. The net savings could accrue even if the medications were much more expensive than current drugs used to treat COPD.

The advantage of going for the cure in COPD has a clear analogy in cancer therapeutic strategies. Highly expensive therapy designed to eliminate, that is cure, cancer is generally regarded as cost effective and clinically relevant. A number of cancers have been successfully treated with this approach. ${ }^{28}$ In contrast, cancer prevention, short of eliminating risk factors such as cigarette smoking, has been strikingly unsuccessful. The lack of success in developing pharmacologic cancer prevention treatments stems from the same clinical limitations that have compromised the development of therapy to alter COPD's natural history, that is, very large studies that require long timeframes. Without a doubt, the prevention of disease progression would be a wonderful clinical tool to have. However, it may be easier to develop treatments that cure the disease, and these should also be actively pursued.

Competing interests Stephen Rennard has served as a consultant or participated in advisory boards for: ABIM, Able Associates, Adelphi Research, Almirall, APT, Aradigm, Argenta, AstraZeneca, BI (ACCP), Biostrategies, BoomCom, Britnall and Nicolini, Capital Research, Chiesi, Clinical Advisors, CommonHealth, Complete Medical Group, Consult Complete,

COPDForum, DataMonitor, Decision Resources, Defined Health, Dey, Dunn Group, Easton Associates, Enterprise Analysis, Equinox, Forest, Fulcrum, Gerson Lehman, GSK Guidepoint, Hoffman LaRoche, IMS, Informed, Inspire, Insyght, KOL Connection, Leerink Swan, M. Pankove, MDRx Financial, MedaCorp, Medimmune, Mpex, Novartis, Nycomed, Oriel, Otsuka, Pearl, Pennside Partners, Pfizer, Pharma Ventures, Pharmaxis, Pick Research, Prescott, PwC, Propagate, Pulmatrix, Pulmonary Reviews, Quadrant, Reckner Associates, Recruiting Resource, Reviews and Trends in COPD/Convergent Health Solutions, Roche, Sacoor, Schering, Schlesinger Medical, Scimed, Smith Research, Sudler and Hennessey, Talecris, Theravance, UBC, Uptake Medical, Vantage Point. He has received lecture fees from: AAAAl, Am Col Osteopathic Physicians, Asan Medical Center, ATS, AstraZeneca, California Soc Allergy, Convergent Health Solutions for Reviews and Trends in COPD, COPD Foundation, Creative Educational Concepts, Dey, Duke, France Foundation, Information TV, University of California-Los Angeles, Network for Continuing Education, Novartis, Nycomed, Otsuka, Pfizer, Sarasota Mem Hospital, Spanish Thoracic Society, University of Washington, University of Alabama-Birmingham, University of Pittsburgh, University of British Columbia, University of California-Davis, VA Sioux Falls. He has received industry-sponsored grants from: AstraZeneca, Biomarck, Centocor, GlaxoSmithKline, Mpex, Nabi, Novartis, Otsuka, Pfizer. Jørgen Vestbo has received fees for consulting and presenting on issues on COPD treatment from the following pharmaceutical companies: GSK, AstraZeneca, Pfizer, Boehringer-Ingelheim, Novartis, Talecris, Chiesi, Hofmann-La Roche and Nycomed none of which provide a cure for COPD, unfortunately.

Provenance and peer review Not commissioned; externally peer reviewed.

Published Online First 8 March 2011

Thorax 2011;66:643-645.

doi:10.1136/thx.2010.151498

\section{REFERENCES}

1. Global Strategy for Diagnosis. Management and Prevention of COPD, 2009. www.goldcopd.com (accessed 2 Mar 2011).
2. Washko GR, Fan VS, Ramsey SD, et al. The effect of lung volume reduction surgery on chronic obstructive pulmonary disease exacerbations. Am J Respir Crit Care Med 2008:177:164-9.

3. Fishman A, Martinez F, Naunheim K, et al. A randomized trial comparing lung-volume-reduction surgery with medical therapy for severe emphysema. N Engl J Med 2003;348:2059-73.

4. Naunheim KS, Wood DE, Mohsenifar Z, et al. Longterm follow-up of patients receiving lung-volumereduction surgery versus medical therapy for severe emphysema by the National Emphysema Treatment Trial Research Group. Ann Thorac Surg 2006;82:431-43

5. Calverley PM, Anderson JA, Celli B, et al. Salmeterol and fluticasone propionate and survival in chronic obstructive pulmonary disease. $N$ Engl J Med 2007;356:775-89.

6. Tashkin DP, Celli B, Senn S, et al. A 4-year trial of tiotropium in chronic obstructive pulmonary disease. N Engl J Med 2008;359:1543-54.

7. Celli BR, Thomas NE, Anderson JA, et al. Effect of pharmacotherapy on rate of decline of lung function in chronic obstructive pulmonary disease: results from the TORCH study. Am J Respir Crit Care Med 2008:178:332-8.

8. Fletcher C, Peto R, Tinker C, et al. The Natural History of Chronic Bronchitis and Emphysema. New York: Oxford University Press, 1976.

9. Anthonisen NR, Connett JE, Kiley JP, et al. Effects of smoking intervention and the use of an inhaled anticholinergic bronchodilator on the rate of decline of FEV1. The Lung Health Study. JAMA 1994;272:1497-505.

10. Anthonisen NR, Connett JE, Murray RP. Smoking and lung function of Lung Health Study participants after 11 years. Am J Respir Crit Care Med 2002;166:675-9.

11. Anthonisen N, Connett J, Friedman B, et al. Design of a clinical trial to test a treatment of the underlying cause of emphysema. Ann N Y Acad Sci 1991:(624 Suppl):31-4.

12. Cazzola M, MacNee W, Martinez FJ, et al. Outcomes for COPD pharmacological trials: from lung function to biomarkers. Eur Respir J 2008;31:416-69.

13. Han MK, Agusti A, Calverley PM, et al. Chronic obstruction pulmonary disease phenotypes: the future of COPD. Am J Respir Crit Care Med 2010;182:598-604.

14. Frey U, Suki B. Complexity of chronic asthma and chronic obstructive pulmonary disease: implications for risk assessment, and disease progression and control. Lancet 2008:372:1088-99.

15. Fabbri LM, Luppi F, Beghé B, et al. Complex chronic comorbidities of COPD. Eur Respir J 2008;31:204-12.

16. Massaro G, Massaro D. Retinoic acid treatment abrogates elastase-induced pulmonary emphysema in rats. Nat Med 1997:3:675-7.

17. Roth MD, Connett JE, D'Armiento JM, et al Feasibility of retinoids for the treatment of emphysema study. Chest 2006;130:1334-45.

18. Hind M, Stinchcombe S. Palovarotene, a novel retinoic acid receptor gamma agonist for the treatment of emphysema. Curr Opin Investig Drugs 2009; 10:1243-50.

19. Hegab AE, Kubo H, Yamaya M, et al. Intranasal HGF administration ameliorates the physiologic and morphologic changes in lung emphysema. $\mathrm{Mol}$ Ther 2008:16:1417-26

20. Ishizawa $\mathbf{K}$, Kubo $\mathbf{H}$, Yamada $\mathbf{M}$, et al. Bone marrow-derived cells contribute to lung regeneration after elastase-induced pulmonary emphysema. FEBS Lett 2004:556:249-52.

21. Krause DS. Engraftment of bone marrow-derived epithelial cells. Ann N Y Acad Sci 2005;1044:117-24.

22. Abe $\mathbf{S}$, Boyer $\mathrm{C}$, Liu $\mathrm{X}$, et al. Cells derived from the circulation contribute to the repair of lung 
injury. Am J Respir Crit Care Med 2004;170:1158-63.

23. Prockop DJ. Repair of tissues by adult stem/ progenitor cells (MSCs): controversies, myths, and changing paradigms. Mol Ther 2009;17:939-46.

24. Ramachandran P, Iredale JP. Reversibility of liver fibrosis. Ann Hepatol 2009;8:283-91.
25. Chatziantoniou C, Dussaule JC. Insights into the mechanisms of renal fibrosis: is it possible to achieve regression? Am J Physiol Renal Physiol 2005;289: F227-34.

26. Cordier JF. Cryptogenic organizing pneumonia. Clin Chest Med 2004;25:727-38, vi-vii.
27. Rennard SI, Umino T, Millatmal T, et al. Evaluation of subclinical respiratory tract inflammation in heavy smokers who switch to a cigarette-like nicotine delivery device that primarily heats tobacco. Nicotine Tob Res 2002:4:467-76

28. Sanghavi DM. How should we tell the stories of our medical miracles? Lancet 2010;375:2068-9.

\section{Howling for the moon}

\section{Neil Barnes, ${ }^{1,2}$ Andrew Bush ${ }^{3,4}$}

Rennard and Vestbo have sounded a ringing call to arms (see page 643). ${ }^{1}$ Instead of trying to make minor improvements in the rate of decline of spirometry in patients with chronic obstructive pulmonary disease (COPD), they call for an all out effort to find a cure. Their arguments have attractions, but we believe that the evidence shows it would be easier to hatch out chickens from a plate of scrambled eggs than to cure COPD in adults.

COPD is defined for epidemiological and most clinical purposes by spirometry. When the underlying pathological changes cause spirometric measures to cross over a given threshold COPD is diagnosed. However, the crossing of this threshold depends on two factors, first the peak lung function attained as a young adult and secondly the deterioration with ageing accelerated by smoking and probably other environmental exposures.

First, some notes of caution. Spirometers are dangerous instruments in many contexts, not least public health. Extensive distal airway obstruction will not be detected by spirometry, and 'a normal' first second forced expired volume $\left(\mathrm{FEV}_{1}\right)$ is very far from being reassuring that all is well. By the time the potential patient with COPD has lost $\mathrm{FEV}_{1}$, extensive and irreparable lung destruction will be present. Although well performed spirometry has a high reproducibility, extensive distal airway obstruction can occur before it is detected. Furthermore, the normal range of spirometry is very

\footnotetext{
'Department of Respiratory Medicine, Barts and the London NHS Trust, London, UK; ${ }^{2}$ Barts and The London School of Medicine and Dentistry, London, UK; ${ }^{3}$ Imperial School of Medicine at National Heart and Lung Institute, London, UK; ${ }^{4}$ Royal Brompton Hospital, London, UK

Correspondence to Andrew Bush, Department of Paediatric Respiratory Medicine, Royal Brompton Hospital, Sydney Street, London SW3 6NP, UK; a.bush@rbh.nthames.nhs.uk
}

wide and so an individual who starts off with very good lung function can still be in the normal range, but for them it is a major loss of lung function.

Peak lung function is reached at 16-18 years in females and $20-25$ years in males. $^{2} 3$ The height of that plateau depends on two factors: the starting point for airway function immediately after birth, and the rate of growth between birth and the time of the physiological plateau. The starting point will be determined by antenatal factors, of which maternal smoking, maternal atopy and maternal nutrition are the most important; ${ }^{4}$ however, other factors such as antenatal exposure to air pollution, ${ }^{5}$ maternal diabetes, chorioamnionitis and maternal antibiotic use may also be significant. ${ }^{4}$ There are likely to be significant gene by environmental interactions, for example null mutations in maternal and fetal GST (glutathione $S$-transferase) exacerbate the effect of tobacco smoke exposure on the fetus. ${ }^{6}$ After birth, a number of cohort studies have delineated what happens to lung function. In the largest and most convincing, there is partial catch up in lung function until age six years in the group with impaired lung function at birth, transient wheezers, but they never attain normal lung function, even twenty years later. It is important to note that no intervention has ever been shown to achieve catch up in growth of airway function at any time period in any context. Factors which likely impact on outcomes include maternal smoking; maternal, paternal and childhood asthma; and childhood respiratory infections. Indeed, combinations of these childhood factors lead to lower lung function in adult life, with no catch-up; a faster rate of decline in lung function; and a greater risk of COPD. Thus, the signal from childhood disadvantage is at least as strong as that from heavy smoking. Exposure to air traffic pollution has been shown to reduce the rate of normal lung growth.
Furthermore, in the CAMP study, 25\% of subjects with mild childhood asthma had reduced growth in airway function irrespective of allocated treatment. Premature delivery and low birth weight are other important factors which impact on longterm lung health. Finally, in all the childhood cohort studies, lung function at best tracks; there is no evidence of any catch-up growth after the preschool years.

It is clearly difficult to determine whether a particular factor operates to the detriment of the individual antenatally or postnatally, or both, but the key message is that a combination of factors may lead to young adults entering the decline phase in lung function at a substantial disadvantage. The best known cause of an accelerated decline in lung function is smoking, but other factors are likely to be important, including air pollution, exposure to biomass fuels in low and middle income countries, and tuberculosis. The evidence about childhood factors causing an accelerated decline in lung function is equivocal. Some studies have shown that a low lung function as a young adult is associated with decline in lung function, but others have not. Aberdonian children with 'wheezy bronchitis' (or episodic viral wheeze, as it would now be termed), who by extrapolation from other studies probably had airway obstruction in the early years), had an accelerated rate of decline in spirometry in middle age. ${ }^{7}$ Again, although this accelerated decline can be halted by, for example, stopping smoking, no treatment has ever been able to ameliorate the normal physiological rate of decline in spirometry, thus undoing the damage of the past.

Finally, the latest long-term follow-up of the Melbourne asthma cohort has just been reported in abstract form. ${ }^{8}$ First, nearly half the subjects with severe childhood asthma recruited at age 10 years had COPD at age 50; and severe asthma in childhood gave a stronger signal than later smoking. Secondly, when the whole cohort was rephenotyped at age 50, those with COPD had (unsurprisingly) lower lung function, which tracked right back to the school age years. Other data which 